\title{
KL-6 levels are elevated in plasma from patients with acute respiratory distress syndrome
}

\author{
H. Sato*ף, M.E.J. Callister", , S. Mumby", G.J. Quinlan\#, K.I. Welsh*, R.M. duBois*, T.W. Evans"
}

KL-6 levels are elevated in plasma from patients with acute respiratory distress syndrome. H. Sato, M.E.J. Callister, S. Mumby, G.J. Quinlan, K.I. Welsh, R. M. duBois, T.W. Evans. (C) ERS Journals Ltd 2004.

ABSTRACT: The acute respiratory distress syndrome (ARDS) is an extreme form of lung injury characterised by disruption to the alveolar epithelium. KL-6 is a mucin-like glycoprotein expressed on type II pneumocytes. Circulating levels of KL-6 have diagnostic and prognostic significance in a number of interstitial lung diseases, and when elevated are thought to indicate disruption of the alveolar epithelial lining. In this study, the authors sought to determine whether plasma KL-6 levels were elevated in patients with ARDS and whether these were associated with aetiology, disease severity, outcome or ventilatory strategy.

Plasma samples were collected from 28 patients with ARDS, nine ventilated controls of matched illness severity and 10 healthy individuals. KL-6 concentrations were measured by enzyme-linked immunosorbent assay.

Patients with ARDS had higher plasma levels of KL-6 (median $537 \mathrm{U} \cdot \mathrm{mL}^{-1}$, interquartile range (IQR) 383-1,119), as compared to ventilated controls (median $255 \mathrm{U} \cdot \mathrm{mL}^{-1}$, IQR 83-338) and normal individuals (median $215 \mathrm{U} \cdot \mathrm{mL}^{-1}$, IQR 149-307). In patients with ARDS, plasma KL-6 levels were higher in nonsurvivors than survivors, and correlated positively with oxygenation index and negatively with arterial oxygen tension:inspiratory oxygen fraction ratio. There were also significant positive correlations with mean and peak airway pressures.

Elevated levels of plasma KL-6 may provide a useful marker for acute respiratory distress syndrome in ventilated patients and have possible prognostic significance. Alveolar epithelial cell damage may be influenced by the nature of mechanical ventilatory support.

Eur Respir J 2004; 23: 142-145.
*Interstitial Lung Disease Unit, and ${ }^{\#}$ Dept of Critical Care Medicine, National Heart and Lung Institute, Imperial College, Royal Brompton Hospital, London, SW3 6NP, UK.

Correspondence: T.W. Evans

Royal Brompton Hospital

Sydney Street

London

SW3 6NP

UK

Fax: 442073518524

E-mail: t.evans@rbh.nthames.nhs.uk

Keywords: Acute lung injury

acute respiratory distress syndrome

KL-6

mechanical ventilation

Received: July 232003

Accepted after revision: October 92003

KL-6 ELISA kits were kindly provided by Eisai Co. (Tokyo, Japan). H. Sato is supported by a grant from Eisai Co.. M.E.J. Callister is supported by a Wellcome Trust Fellowship. This work was supported partly by the British Lung Foundation and the Dunhill Medical Trust. ${ }^{\top}$ Joint first authors.
KL-6 is a mucin-like glycoprotein expressed on epithelial cells. Serum levels of KL-6 are elevated in a variety of respiratory and nonrespiratory conditions, including breast and pancreatic cancer [1, 2], and diabetes mellitus [3]. However, most attention has focused on KL-6 as a diagnostic and prognostic tool in respiratory disease. Thus, serum KL-6 levels are elevated and correlate with disease activity in patients with interstitial pneumonia [4], alveolar proteinosis [5], pulmonary sarcoidosis [6] and radiation pneumonitis [7]. Immunohistochemical studies have shown that KL-6 is strongly expressed on type II pneumocytes, and serum KL-6 levels are regarded as an index of alveolar epithelial cell damage and subsequent regeneration [8, 9]. Moreover, serum KL-6 levels have been shown to correlate with indices of alveolar-capillary permeability [10], suggesting a link between serum KL-6 and alveolar epithelial barrier dysfunction.

The acute respiratory distress syndrome (ARDS) in adults is an extreme form of lung injury characterised by refractory hypoxaemia developing in the presence of radiological evidence of bilateral pulmonary infiltrates. Damage to, and disruption of, the alveolar epithelial lining is a key feature in the pathophysiology of ARDS, and leads to the development of pulmonary oedema and respiratory failure. Furthermore, inappropriate ventilatory strategies that lead to the cyclical opening and closing of atelectatic alveoli, together with alveolar overdistention, can worsen pre-existing lung injury. Consequently, ventilatory strategies developed recently now aim to limit shear forces applied to the lung parenchyma through the application of low tidal volumes $\left(6 \mathrm{~mL} \cdot \mathrm{kg}^{-1}\right.$ predicted body weight) and limited airway pressures (plateau pressure $<30 \mathrm{cmH}_{2} \mathrm{O}$ ), an approach associated with significant falls in mortality [11].

The aims of this study were, first, to ascertain whether plasma levels of KL-6 were elevated in ARDS compared to appropriate controls. Secondly, the authors wanted to determine whether plasma levels of this glycoprotein were related to aetiology, disease severity, outcome or ventilatory strategy.

\section{Materials and methods}

Plasma samples were collected from 28 patients with ARDS (16 consecutive survivors 1998-2002 and 12 consecutive nonsurvivors 1996-2001), nine ventilated patients without lung injury and 10 healthy controls. Initial samples were collected from patients with ARDS at the earliest possible time after the patient met defining criteria [12] or as soon as was clinically possible after admission to the current authors' intensive care unit (ICU). Thus, 12 patients were admitted to 
other ICUs prior to transfer to the authors' institution. Taking this into account, the total median duration of ARDS at the time of initial sample collection was 6.5 days. Nineteen of the patients with ARDS had a further sample collected later during their clinical course (median interval between samples 11 days).

Clinical information recorded included age, sex, aetiology of lung injury and details of past medical history (including incidence of diabetes mellitus and malignant disease). Illness severity (assessed using the Sequential Organ Failure Assessment (SOFA) score [13]) and respiratory/ventilatory parameters (oxygenation index, arterial oxygen tension $\left(\mathrm{Pa}, \mathrm{O}_{2}\right)$ :inspiratory oxygen fraction $\left(\mathrm{Fi}, \mathrm{O}_{2}\right)$ ratio, arterial carbon dioxide tension $\left(\mathrm{Pa}, \mathrm{CO}_{2}\right)$, tidal volume, peak airway pressure, mean airway pressure and positive end-expiratory pressure (PEEP)) were recorded for patients (at the time of early sample collection) and ventilated controls. The oxygenation index was the product of $\mathrm{Fi}, \mathrm{O}_{2}$ and mean airway pressure $/ \mathrm{Pa}, \mathrm{O}_{2}$.

The study protocol was approved by the Royal Brompton and Harefield Trust Research Ethics Committee. Informed written consent was obtained for healthy control patients and assent from relatives was obtained for ventilated patients. The plasma level of KL-6 was measured by an enzyme-linked immunosorbent assay (ELISA) using a KL-6 antibody kit (ED046; Eisai Co., Tokyo, Japan), as described previously [14].

All ELISA measurements were made in duplicate and results are expressed as median values and interquartile ranges (IQR). Comparisons between three groups were made using a Kruskal-Wallis test and comparisons between two groups were made using a two-tailed Mann-Whitney U-test. A p-value of $<0.05$ was considered significant. Correlations between variables were assessed using Spearman nonparametric analysis.

\section{Results}

Demographic and clinical information for patients and controls are shown in table 1 . The patients with ARDS and the ventilated control group were well matched for illness severity, although the former were significantly younger.
However, there was no relationship between age and plasma KL-6 concentration in the study population as a whole.

The aetiologies of lung injury were pneumonia $(35.7 \%)$, post-lung resection $(21.4 \%)$, sepsis $(17.8 \%)$, blood transfusion reaction $(7.1 \%)$, aspiration pneumonia $(7.1 \%)$, post cardiopulmonary bypass $(3.6 \%)$, severe trauma $(3.6 \%)$ and pancreatitis $(3.6 \%)$. The ventilated control group were patients ventilated following cardiac surgery $(n=6$; three post-aortic valve replacement, two post-coronary artery bypass grafting, one post-closure of atrial septal defect), due to cardiomyopathy $(n=1)$ and hypercapnic respiratory failure without evidence of parenchymal lung disease $(n=2)$. Two patients with ARDS and three ventilated controls had pre-existing diabetes mellitus $(p>0.05)$. No patients in the study had known malignant disease. Oxygenation indices, $\mathrm{Pa}, \mathrm{CO}_{2}$ levels and mean airway pressures were significantly higher in the ARDS population than in the ventilated controls. $P a, \mathrm{O}_{2}$ : $\mathrm{Fi}, \mathrm{O}_{2}$ ratios were significantly lower in patients with ARDS (table 1).

Plasma KL-6 concentrations were significantly elevated in the early plasma sample taken from patients with ARDS (537 U.mL $\mathrm{mL}^{-1}$, IQR 383-1,119), as compared to both ventilated $\left(255 \mathrm{U} \cdot \mathrm{mL}^{-1}, \mathrm{IQR} 83-338, \mathrm{p}<0.001\right)$ and nonventilated healthy $\left(215 \mathrm{U} \cdot \mathrm{mL}^{-1}\right.$, IQR $\left.149-307, \mathrm{p}<0.001\right)$ controls, but no significant difference emerged between levels in the ventilated and nonventilated control groups (fig. 1a). KL-6 concentrations remained elevated in samples collected from patients later in the course of ARDS compared to both ventilated and healthy controls $(\mathrm{p}<0.001$ for both comparisons; table 1$)$. There was no significant difference between KL-6 levels in the early and late samples.

There was no difference between plasma KL-6 concentrations from patients with ARDS of pulmonary or extra pulmonary origin $\left(679 \mathrm{U} \cdot \mathrm{mL}^{-1}\right.$, IQR 402-1381 versus $499 \mathrm{U} \cdot \mathrm{mL}^{-1}$, IQR 329-1194, respectively, $\mathrm{p}=0.47$ ). Furthermore, there was no correlation between plasma KL-6 and global illness severity as assessed by SOFA score (table 2). However, significant correlations were demonstrated between plasma KL-6 concentration and oxygenation index $(\mathrm{p}<0.01, \mathrm{r}=0.57)$ and $\mathrm{Pa}, \mathrm{O}_{2}: \mathrm{Fi}_{1} \mathrm{O}_{2}$ ratio $(\mathrm{p}<0.05, \mathrm{r}=-0.39)$ in patients with ARDS (table 2).

Survivors and nonsurvivors with ARDS displayed significant differences in SOFA score, oxygenation index, tidal volume

Table 1.-Demographic information, illness severity scores, respiratory and ventilatory parameters, and plasma KL-6 concentrations for patients with acute respiratory distress syndrome (ARDS), ventilated controls and healthy controls

\begin{tabular}{|c|c|c|c|c|}
\hline Parameter & ARDS patients ${ }^{\#}$ & Ventilated controls & Healthy controls & $\begin{array}{l}\text { ARDS versus } \\
\text { ventilated controls }\end{array}$ \\
\hline
\end{tabular}

Subjects $\mathrm{n}$
Age yrs
Sex \% female
Diabetic \% patients
SOFA score
Oxygenation index $\mathrm{cmH}_{2} \mathrm{O} \cdot \mathrm{mmHg}^{-1}$
${\mathrm{~Pa}, \mathrm{O}_{2}: \mathrm{Fi}_{1} \mathrm{O}_{2} \text { ratio } \mathrm{kPa}}_{\mathrm{Pa}, \mathrm{CO}_{2} \mathrm{kPa}}$
Tidal volume $\mathrm{mL} \cdot \mathrm{kg}$ predicted weight
Peak airway pressure $\left(\mathrm{cmH}_{2} \mathrm{O}\right)$
Mean airway pressure $\left(\mathrm{cmH}_{2} \mathrm{O}\right)$
PEEP cmH
KL-6 concentration units $\cdot \mathrm{mL}^{-1}$
Early sample
Late sample

28
$39.5(23.0-61.5)$
64.2
$2(7)$
$6.0(3.5-9.0)$
$13.5(10.7-22.0)$
$16.4(12.4-20.1)$
$8.1(7.2-8.9)$
$8.9(7.1-10.2)$
$33.0(30.5-36.5)$
$22.0(16.5-24.0)$
$10.0(6.0-12.0)$

9

$68.0(49.0-75.0)$

33.3

$3(33)$

$7.0(2.5-9.5)$

$5.9(4.2-9.2)$

$33.3(28.2-35.2)$

$5.8(4.9-6.8)$

$9.6(6.5-11.7)$

$26.0(20.0-36.0)$

$14.0(11.0-17.0)$

$6.0(5.0-10.0)$

537 (383-1119)

$670(388-1386)$

255 (83-338)

255 (83-338)

10
$31.5(29.0-34.0)$
30.0
$0(0)$

215 (149-307) 215 (149-307)

$$
\begin{aligned}
& p<0.05 \\
& p=0.14 \\
& p=0.07 \\
& p=0.95 \\
& p<0.01 \\
& p<0.001 \\
& p<0.01 \\
& p=0.59 \\
& p=0.13 \\
& p<0.05 \\
& p=0.11
\end{aligned}
$$

$\mathrm{p}<0.001$ $\mathrm{p}<0.001$

Data are presented as median (interquartile range or \%). SOFA: Sequential Organ Failure Assessment; $P$ a $, \mathrm{O}_{2}:$ arterial oxygen tension; $F 1, \mathrm{O}_{2}$ : inspiratory oxygen fraction; $\mathrm{Pa}, \mathrm{CO}_{2}$ : arterial carbon dioxide tension; PEEP: positive end-expiratory pressure. \# : clinical information recorded at time of early plasma sample collection. 


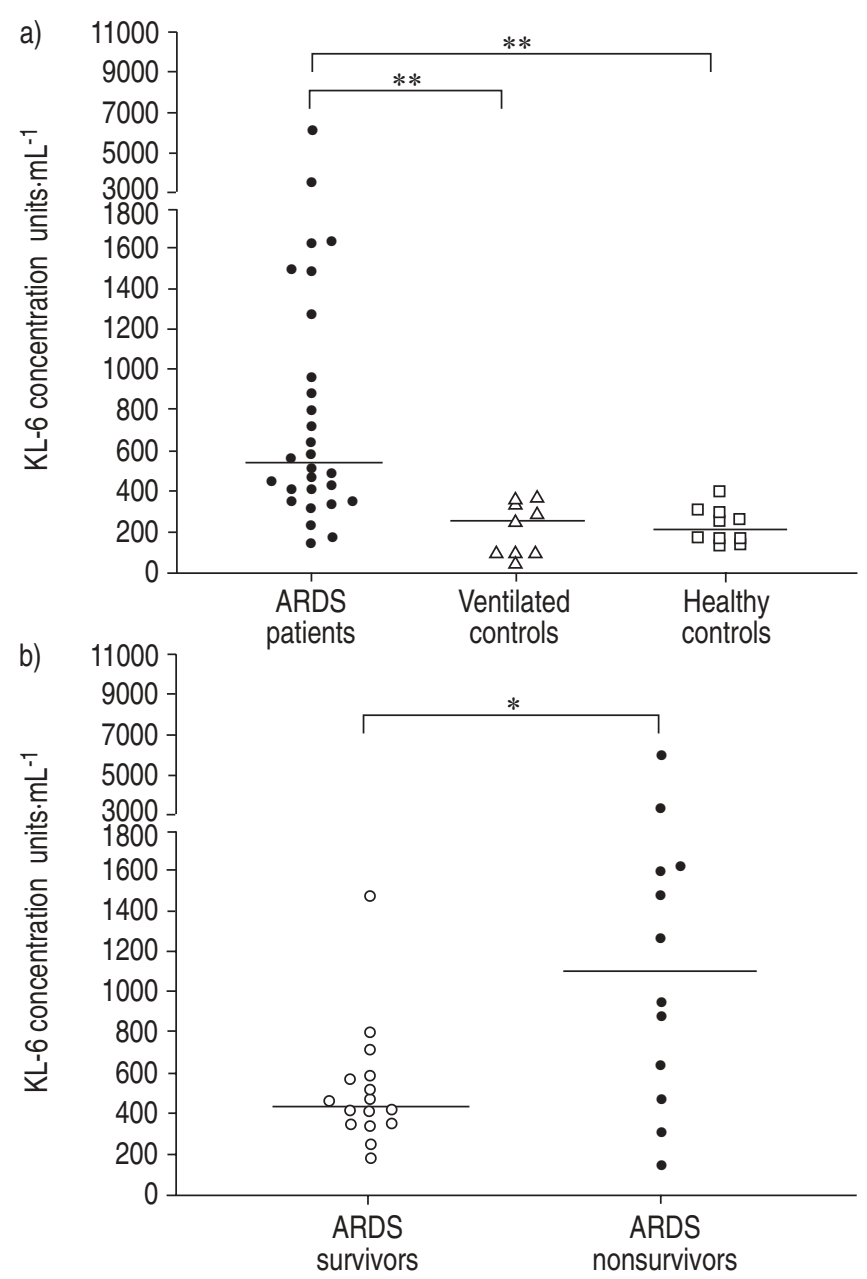

Fig. 1. - Plasma KL-6 concentrations in a) patients with acute respiratory distress syndrome (ARDS) (early sample), ventilated controls and healthy controls, and b) ARDS survivors and nonsurvivors (early samples). Horizontal line indicates median value. *: $\mathrm{p}<0.05$; **: $\mathrm{p}<0.001$.

and mean airway pressure (all higher in the nonsurviving group (table 3)). $\mathrm{Pa}, \mathrm{O}_{2}: \mathrm{Fi}_{1} \mathrm{O}_{2}$ ratios were significantly lower in nonsurviving patients. Plasma KL-6 concentrations were
Table 2.-Correlation analysis between plasma KL-6 concentration (early sample) and illness severity scores and respiratory/ventilatory parameters (recorded at time of early sample collection)

Clinical parameter

Correlation with plasma $\mathrm{KL}-6$ units $\cdot \mathrm{mL}^{-1}$

SOFA score

Oxygenation index $\mathrm{cmH}_{2} \mathrm{O} \cdot \mathrm{mmHg}^{-1}$

$\mathrm{p}=0.35, \mathrm{r}=0.18$

$\mathrm{Pa}, \mathrm{O}_{2}: \mathrm{Fi}_{1} \mathrm{O}_{2}$ ratio $\mathrm{kPa}$

$\mathrm{Pa}, \mathrm{CO}_{2} \mathrm{kPa}$

Tidal volume $\mathrm{mL} \cdot \mathrm{kg}$ pred body weight ${ }^{-1}$

Peak airway pressure $\mathrm{cmH}_{2} \mathrm{O}$

Mean airway pressure $\mathrm{cmH}_{2} \mathrm{O}$

PEEP $\mathrm{cmH}_{2} \mathrm{O}$

$\mathrm{p}=0.35, \mathrm{r}=0.18$
$\mathrm{p}<0.01, \mathrm{r}=0.57$

$\mathrm{p}<0.05, \mathrm{r}=-0.39$

$\mathrm{p}=0.83, \mathrm{r}=0.04$

$\mathrm{p}=0.06, \mathrm{r}=0.37$

$\mathrm{p}<0.01, \mathrm{r}=0.54$

$\mathrm{p}<0.05, \mathrm{r}=0.51$

$\mathrm{p}=0.14, \mathrm{r}=0.30$

SOFA: Sequential Organ Failure Assessment; $\mathrm{Pa}_{2} \mathrm{O}_{2}$ : arterial oxygen tension; $\mathrm{Fi}_{1} \mathrm{O}_{2}$ : inspiratory oxygen fraction; $\mathrm{Pa}, \mathrm{CO}_{2}$ : arterial carbon dioxide tension; PEEP: positive end-expiratory pressure.

higher in nonsurviving patients, as compared to survivors in both early and late plasma samples $(\mathrm{p}<0.05$ and $\mathrm{p}<0.01$ respectively; fig. $1 \mathrm{~b}$ and table 3 ).

Within the ARDS population, there was a significant positive correlation between plasma KL-6 concentration in the early sample and both peak and mean airway pressures at the time of early sample collection (table 2).

\section{Discussion}

This study demonstrates elevated levels of KL-6 in plasma from patients with ARDS when compared to ventilated controls of matched illness severity and healthy controls. These results suggest that increased plasma levels of KL-6 in patients with ARDS reflect the pathophysiology of lung injury, rather than representing a nonspecific effect of mechanical ventilation or critical illness. Furthermore, these results are not explained by the incidence of other conditions known to cause elevated KL-6 levels in plasma (e.g. diabetes mellitus, malignant disease or other interstitial lung disease).

Secondly, significant correlations between plasma KL-6 levels and indices of lung injury severity (oxygenation index and $\mathrm{Pa}, \mathrm{O}_{2}: \mathrm{Fi}_{1} \mathrm{O}_{2}$ ratio) have been shown for the first time within the

Table 3. - Demographic information, illness severity scores, respiratory and ventilatory parameters, and KL-6 concentrations for acute respiratory distress syndrome (ARDS) survivors and nonsurvivors

\begin{tabular}{|c|}
\hline Parameter \\
\hline
\end{tabular}

Subjects $n$

Age yrs

Sex $\%$ female

Diabetic $\%$ patients

SOFA score

Oxygenation index $\mathrm{cmH}_{2} \mathrm{O} \cdot \mathrm{mmHg}^{-1}$

$P \mathrm{a}, \mathrm{O}_{2}: F_{1}, \mathrm{O}_{2}$ ratio $\mathrm{kPa}$

$\mathrm{Pa}, \mathrm{CO}_{2} \mathrm{kPa}$

Tidal volume $\mathrm{mL} \cdot \mathrm{kg}$ predicted weight ${ }^{-1}$

Peak airway pressure $\mathrm{cmH}_{2} \mathrm{O}$

Mean airway pressure $\mathrm{cmH}_{2} \mathrm{O}$

$\mathrm{PEEP} \mathrm{CmH}_{2} \mathrm{O}$

KL-6 concentration units $\cdot \mathrm{mL}^{-1}$

Early sample

Late sample

16
$36.0(23.0-71.0)$
56.2
$1(6)$
$4.0(3.0-6.5)$
$12.2(9.6-16.7)$
$19.4(17.9-22.6)$
$8.5(7.2-9.2)$
$8.1(5.9-9.6)$
$32.0(29.0-36.0)$
$19.0(14.0-23.0)$
$8.5(5.5-10.0)$
$441(351-571)$
$453(368-616)$

12

$$
\begin{gathered}
40.5(24.0-50.5) \\
75.0 \\
1(8) \\
9.0(6.5-11.5) \\
24.3(14.0-52.3) \\
11.5(8.6-14.3) \\
7.6(7.2-8.4) \\
10.2(8.8-10.8) \\
35.5(32.0-38.5) \\
24.5(19.0-27.0) \\
10.0(9.0-13.0)
\end{gathered}
$$

$\mathrm{p}=0.59$

$\mathrm{p}=0.43$

$\mathrm{p}=1.0$

$\mathrm{p}<0.01$

$\mathrm{p}<0.05$

$\mathrm{p}<0.001$

$\mathrm{p}=0.39$

$\mathrm{p}<0.05$

$\mathrm{p}=0.06$

$\mathrm{p}<0.05$

$\mathrm{p}=0.11$

$1119(563-1629)$ 1323 (933-4160) $\mathrm{p}<0.05$

$\mathrm{p}<0.01$

Data are presented as median (interquartile range or \%). SOFA: Sequential Organ Failure Assessment; $P$ a, $\mathrm{O}_{2}$ : arterial oxygen tension; $F \mathrm{i}, \mathrm{O}_{2}$ : inspiratory oxygen fraction; $\mathrm{Pa}, \mathrm{CO}_{2}$ : arterial carbon dioxide tension; PEEP: positive end-expiratory pressure. ${ }^{\#}$ : clinical information recorded at time of early plasma sample collection. 
ARDS population. There was no relationship between KL-6 and global illness severity, as measured by the SOFA score.

Thirdly, a significant difference in KL-6 levels between survivors and nonsurvivors of ARDS has been demonstrated. Lung injury and primary respiratory failure are not considered to be principal causes of mortality in patients with ARDS, and the majority of nonsurviving patients in this study died from multiple organ failure. The current findings therefore suggest a possible relationship between disruption of the alveolar epithelium and poor outcome in ARDS.

Finally, significant relationships have been shown between plasma KL-6 concentrations and certain ventilatory parameters. KL-6 levels correlated with peak and mean airway pressure, and there was a trend towards a statistically significant relationship with tidal volume, possibly indicating an association between ventilatory strategy and alveolar cell damage in ARDS. The majority of patients entered into this study were recruited prior to the publication of the ARDSNet trial of low tidal volume ventilation in ARDS [11]. Some were therefore ventilated using tidal volumes that exceeded the recommended limit of $6 \mathrm{~mL} \cdot \mathrm{kg}$ body weight ${ }^{-1}$ (plateau pressures were not recorded on the archived database). However, KL-6 levels remain significantly higher in the ARDS population, as compared to both control populations, even when patients ventilated with tidal volumes $>6 \mathrm{~mL} \cdot \mathrm{kg}^{-1}$ were excluded from analysis $(\mathrm{p}<0.05$; data not shown).

These data suggest that elevated levels of plasma KL-6 may provide a useful marker for acute respiratory distress syndrome in ventilated patients. Secondly, the finding that plasma KL-6 levels relate to severity of lung injury and mortality suggests a link between disruption of the alveolar epithelial lining and a poor outcome in acute respiratory distress syndrome. Finally, the relationship between plasma KL-6 concentration and airway pressures in mechanical ventilation is consistent with the hypothesis that ventilatory strategy influences alveolar epithelial damage in this syndrome.

\section{References}

1. Ogawa $\mathrm{Y}$, Ishikawa $\mathrm{T}$, Ikeda $\mathrm{K}$, et al. Evaluation of serum KL-6, a mucin-like glycoprotein, as a tumor marker for breast cancer. Clin Cancer Res 2000; 6: 4069-4072.

2. Kohno $\mathrm{N}$, Inoue $\mathrm{Y}$, Hamada $\mathrm{H}$, et al. Difference in sero-diagnostic values among KL-6-associated mucins classified as cluster 9. Int J Cancer Suppl 1994; 8: 81-83.
3. Takahashi T, Takamura K, Sakaue S, Ishii J, Yokouchi H, Nasuhara Y. Elevated serum KL-6 concentrations in patients with diabetes mellitus. $J$ Diabetes Complications 2002; 16: 352-358.

4. Kobayashi J, Kitamura S. KL-6: a serum marker for interstitial pneumonia. Chest 1995; 108: 311-315.

5. Takahashi T, Munakata M, Suzuki I, Kawakami Y. Serum and bronchoalveolar fluid KL-6 levels in patients with pulmonary alveolar proteinosis. Am J Respir Crit Care Med 1998; 158: 1294-1298.

6. Kobayashi J, Kitamura S. Serum KL-6 for the evaluation of active pneumonitis in pulmonary sarcoidosis. Chest 1996; 109: 1276-1282.

7. Hamada H, Kohno N, Akiyama M, Hiwada K. Monitoring of serum KL-6 antigen in a patient with radiation pneumonia. Chest 1992; 101: 858-860.

8. Kohno N, Awaya Y, Oyama T, et al. KL-6, a mucin-like glycoprotein, in bronchoalveolar lavage fluid from patients with interstitial lung disease. Am Rev Respir Dis 1993; 148: 637-642.

9. Kuwano $\mathrm{K}$, Maeyama $\mathrm{T}$, Inoshima $\mathrm{I}$, et al. Increased circulating levels of soluble Fas ligand are correlated with disease activity in patients with fibrosing lung diseases. Respirology 2002; 7: 15-21.

10. Inoue Y, Barker E, Daniloff E, Kohno N, Hiwada K, Newman LS. Pulmonary epithelial cell injury and alveolarcapillary permeability in berylliosis. Am J Respir Crit Care Med 1997; 156: 109-115.

11. Ventilation with lower tidal volumes as compared with traditional tidal volumes for acute lung injury and the acute respiratory distress syndrome. The Acute Respiratory Distress Syndrome Network. N Engl J Med 2000; 342: 13011308.

12. Bernard GR, Artigas A, Brigham KL, et al. The AmericanEuropean Consensus Conference on ARDS. Definitions, mechanisms, relevant outcomes, and clinical trial coordination. Am J Respir Crit Care Med 1994; 149: 818-824.

13. Vincent JL, Moreno R, Takala J, et al. The SOFA (Sepsisrelated Organ Failure Assessment) score to describe organ dysfunction/failure. On behalf of the Working Group on Sepsis-Related Problems of the European Society of Intensive Care Medicine. Intensive Care Med 1996; 22: 707-710.

14. Ohnishi H, Yokoyama A, Kondo K, et al. Comparative study of KL-6, surfactant protein-A, surfactant protein-D, and monocyte chemoattractant protein-1 as serum markers for interstitial lung diseases. Am J Respir Crit Care Med 2002; 165: 378-381. 